Article

\title{
NEV's Supply Chain Coordination with Financial Constraint and Demand Uncertainty
}

\author{
Xin $\mathrm{Li}^{+}\left(\mathbb{D}\right.$, Yongjian $\mathrm{Li}^{*}+\boldsymbol{+}^{+}$
}

\author{
Department of Decision Sciences, Macau University of Science and Technology, Macau, China; xli@must.edu.mo \\ * Correspondence: 1809853GBM30005@student.must.edu.mo \\ + These authors contributed equally to this work.
}

\begin{abstract}
Sustainable development coordination can facilitate the new energy vehicles (NEV) supply chain. By a coordinating supply contract, the operating costs can be reduced and supply chain competitiveness can be improved. We designed a revenue-sharing and buy-back (RSBB) contract to coordinate the supply chain with the cash-strapped retailer or manufacturer and analyzed the impact of the acceptable bankruptcy risk and own fund on the optimal order quantity, supply chain profits, and coordinating factors, including revenue share and buy-back price. Interestingly, the revenue share decreases in the acceptable bankruptcy risk, but the buy-back price increases in the acceptable bankruptcy risk when the retailer has financial constraints. However, when the manufacturer has financial constraints, the revenue share increases in the acceptable bankruptcy risk, but the buy-back price decreases in the acceptable bankruptcy risk.
\end{abstract}

Keywords: supply chain finance; new energy vehicles (NEV); bankruptcy risk; revenue-sharing contract; buy-back contract

\section{Introduction}

Advances in social science and technology have improved lives but also raised the problems of resource scarcity and environmental pollution. The development of the new energy vehicle (NEV) industry is important for the improvement of air quality and the reduction of carbon emissions. Increasingly, countries are taking the initiative to promote the development of NEVs [1]. Compared with traditional vehicles, NEVs have the following advantages: (1) zero carbon footprint; (2) reduction of water pollution caused by oil spills; (3) reduction of greenhouse gas emissions; (4) stable operation and low noise. Therefore, NEV development reduces total energy consumption and pollutant emissions. Due to the pursuit of green development, supply chain sustainability has become a hot topic in both academia and industry.

In the NEV supply chain, a retailer orders from the manufacturer based on demand forecasts to match supply with the uncertain demand. While retailers can earn the difference between wholesale and retail prices, they are exposed to the sales risk associated with uncertain demand. However, the risk cannot push the manufacturer to reduce their wholesale price but can reduce the retailer's order size. Then, double marginalization happens and the supply chain is inefficient. In 2020, a study on consumers' low-carbon preferences in the NEV market also showed that double marginalization would lead to a lower profit for both manufacturer and retailers than that under the centralized decision [2]. Double marginalization is detrimental to the long-term development of the NEV industry [3]. With the increasing awareness of environmental protection, more consumers prefer NEVs. In order to achieve the sustainable development of the NEV supply chain, the contract design of the NEV supply chain has practical significance. Gong et al. [2] designed a revenue-sharing (RS) contract to eliminate the double marginalization. Yu et al. [4] designed a cost-sharing (CS) contract to coordinate the NEV supply chain to obtain Pareto 
improvement. In fact, NEV supply chain contract design faces many specific situations, such as financial constraints. In our study, we designed a revenue-sharing and buy-back (RSBB) contract to coordinate the supply chain with financial constraints.

To reduce the environmental deterioration and realize sustainable development, a lot of capital needs to be invested in R\&D to develop green and clean products. For the NEV industry, the dependence on capital is high. Due to the uncertainty of technological innovation and the lag of revenue, NEV manufacturers have a long account receivable collection period, so they have financial constraints. Retailers are usually small- and medium-sized enterprises, and they do not have enough capital. Considering the cost of sales, a retailer usually places a prototype car in the store. If a customer places an order, the retailer will further order the car from the manufacturer. With this operating strategy, customers will have to wait several months to receive their cars. The experience is less favorable and is not conducive to the promotion of NEVs. The shortage of funds restricts the daily operation of the enterprise and the business development of the enterprise. The serious shortage of funds even leads to the bankruptcy of the enterprise [5]. In supply chain management, the capital problem of a node enterprise may be transmitted to other partners in the supply chain, and the whole chain may fall into financial difficulties [6]. Therefore, to face uncertain demand in the market, it is especially important to study the sustainable development of the NEV supply chain under financial constraints. More specifically, we will answer the following research questions: (1) How does the supply chain make consistent decisions when demand is uncertain and financial constraints exist? (2) What kind of contract can fully coordinate the supply chain? (3) How do supply chain coordinating factors affect the profitability of the entire supply chain in the face of demand uncertainty?

In our study, we consider the financial constraints of a manufacturer or retailer, respectively, to design a revenue-sharing and buy-back contract to coordinate the supply chain and analyze the impact of acceptable bankruptcy risk on the optimal decisions, coordinating factors, and the supply chain parties' profits. When a retailer has financial constraints, to encourage the retailer to increase order size, a manufacturer offers the retailer a lower wholesale price before the sales season and promises to share revenue with the retailer. At the end of the sales season, the manufacturer will buy back the remaining products. We also analyze the case when a manufacturer has financial constraints. Finally, we compare the results in the two cases. Our main results are as follows:

1. We study the coordination through revenue-sharing and buy-back (RSBB) contracts when a member of the NEV supply chain has financial constraints and analyze the acceptable bankruptcy risk impact on optimal order quantity, which has not been involved in previous literature.

2. We investigate the impact of acceptable bankruptcy risk on the optimal decision making when a retailer has a financial constraint. In both decisions, there exists a fixed acceptable value of bankruptcy risk, below which the retailer's optimal order quantity increases in the risk, but above which it remains constant. Under the RSBB contract, if the retailer has a low acceptable risk of bankruptcy, the supply chain can be coordinated by increasing the revenue sharing ratio and reducing the buy-back price. Similarly, we investigate the impact of acceptable bankruptcy risk on optimal decision-making when a manufacturer is financially constrained. Under the RSBB contract, if the manufacturer has a high preference for acceptable bankruptcy risk, then the supply chain should be coordinated by reducing the revenue sharing ratio and increasing the buy-back price.

The remainder of this paper is organized as follows: We review the literature in Section 2 and present the model in Section 3. In Sections 4 and 5, we discuss the supply chain coordination decisions under the financial constraint of the retailer or manufacturer, respectively. We present our conclusion in Section 6. The proofs of all propositions are relegated to the Appendix A. 


\section{Literature Review}

The literature can be classified into two types: one is on sustainable supply chain management (SSCM), and the other is on supply chain financing (SCF).

In the field of SSCM, the literature can be classified into three types: qualitative studies on policies, empirical studies $[7,8]$ on consumers' willingness to purchase [9], and studies on profit distribution mechanisms [10]. Our study is on profit distribution mechanisms. Linton et al. [11] consider the convergence of SSCM. Carter and Rogers [12,13] propose a framework for SSCM and conduct a systematic review of the literature to describe the evolution and future direction of SSCM. The authors of [14] identify the key categories of SSCM and related practices needed to fulfill sustainability requirements, thereby contributing to improved sustainability performance. Dubey et al. [15] propose a new framework and further research directions for SSCM. Sustainability issues attract the attention of enterprises. Corporate sustainability (CS) plans are often closely linked to corporate social responsibility (CSR). These research works examine the coordination of supply chains from a CSR context [16-18]. In SSCM, Closs et al. [19] consider include channel selection, market decisions, sourcing, alternative energy platforms, and security. Recently, Hong and Guo [20] examined supply chain contracts of green products from the perspective of environmental responsibility.

SCF is a hot topic in supply chain management in recent years. Kouvelis and Zhao [21-23] study a supply chain in which a supplier sells a wholesale-price (WP) contract to a financially constrained retailer facing stochastic demand. They also optimize the problem of trade credit (TC) contracts from the supplier's perspective when both are financially constrained and at risk of bankruptcy, and finally, design a contractual coordination supply chain considering bankruptcy costs. Feng et al. [24] consider the budget constraints of the supply chain members and the cost of capital, and the RSBB contract is designed to coordinate the supply chain. Xiao et al. [25] consider the retailer's financial constraints and inability to borrow from banks, but the supplier can borrow and provide TC contracts to the retailer to alleviate its financial constraints. However, with suppliers selling to a retailer facing stochastic demand, classical coordination contracts cannot coordinate suppliers' production and retailers' purchasing decisions to achieve effective performance [26]. Especially in the context of sustainable development, investment is always limited by the financial constraints of emerging suppliers [27], as the case of NEVs (SC). Some incentives are needed to encourage manufacturers to participate in low-carbon supply chains [28]. Xin et al. [29] study the coordination of emerging supply chains with demand uncertainty. Our work is positioned in the crossing field of SSCM and SCF. Specifically, under the NEV supply chain capital constraint and uncertain demand, it is a study of contract design with consideration of the acceptable bankruptcy risk. The objective of the study is to realize the sustainable development of the NEV supply chain. More related works can be found in Table 1.

Table 1. Comparison of the contributions of related literature.

\begin{tabular}{|c|c|c|c|c|c|c|}
\hline $\begin{array}{r}\text { Related } \\
\text { Literature }\end{array}$ & Sustainability & $\begin{array}{c}\text { Uncertainty } \\
\text { Demand }\end{array}$ & $\begin{array}{c}\text { Bankruptcy } \\
\text { Risk }\end{array}$ & Constraint & Contract & Year \\
\hline [21-23] & $x$ & $\sqrt{ }$ & $\sqrt{ }$ & Financial constraints & WP, RS & $2011,2012,2016$ \\
\hline [24] & $x$ & $\sqrt{ }$ & $x$ & Budget constraints & RSBB & 2015 \\
\hline [26] & $x$ & $\sqrt{ }$ & $x$ & $x$ & APD & 2016 \\
\hline$[25]$ & $x$ & $\sqrt{ }$ & $\sqrt{ }$ & Financial constraints & $\mathrm{RS}, \mathrm{BB}, \mathrm{QD}$ & 2017 \\
\hline [16-18] & CSR & $x$ & $x$ & $x$ & RS & 2014, 2014, 2017 \\
\hline [28] & Low Carbon & $x$ & $x$ & $x$ & CS, RS & 2019 \\
\hline [27] & Green SC & $\sqrt{ }$ & $\sqrt{ }$ & Financial constraints & IS & 2019 \\
\hline [29] & Green SC & $\sqrt{ }$ & $x$ & $x$ & WP, RGMS, TPTF & 2020 \\
\hline [2] & NEV SC & $\sqrt{ }$ & $x$ & $x$ & RS & 2020 \\
\hline our study & NEV SC & $\sqrt{ }$ & $\sqrt{ }$ & Financial constraints & RSBB & \\
\hline
\end{tabular}




\section{Model Setup}

In this section, we first specify the basic model setup. We consider a supply chain with financial constraints, in which there is one manufacturer with financial constraints and one retailer. The retailer puts an order to the manufacturer. According to the order quantity, the manufacturer prepares the production. Sometimes, the retailer's capital is not enough to cover the purchasing cost. As a result, the retailer needs to loan money and pay an interest rate for the loan. Because of the capital gap (the purchasing cost minus the retailer's capital) and the random demand for the products, the retailer needs to burden the bankruptcy risk. The capital gap and risk may affect the retailer's order decision. The parameters in the model is as follows Table 2:

Table 2. Notation.

\begin{tabular}{rll}
\hline Symbol & Description & Hypotheses \\
\hline$p$ & The market price per unit & \\
$w$ & The wholesale price per unit & \\
$c$ & The manufacturing cost per unit & \\
$s$ & The salvage value per unit & \\
$b$ & Buy-back price & \\
$\theta$ & Revenue share of the retailer per unit & $0<\theta<1$ \\
$q$ & The order quantity set by the retailer & \\
$B$ & Own funds of supply chain members & \\
$r$ & Interest rate for the loan & $0<r<1$ \\
$\alpha$ & Acceptable bankruptcy risk & $0<\alpha<1$ \\
$x$ & The customer demand & $x \geqslant 0$ \\
$F(\cdot)$ & The Cumulative Distribution Function $(\mathrm{CDF})$ of the demand & $0<F(\cdot) \leqslant 1$ \\
$F^{-1}(\cdot)$ & The inverse function of $F(\cdot)$ & $x:=F^{-1}(\cdot) \geqslant 0$ \\
\hline
\end{tabular}

\section{The Coordination When Retailer Has Financial Constraints}

In this part, the retailer needs to pay when he/she orders the goods, such that the retailer has financial constraints. In this part, we design a revenue-sharing and buy-back contract to coordinate the supply chain.

We will consider centralized decisions and decentralized decisions when the retailer has financial constraints and needs to borrow money from a bank at an interest cost $(w q-B)^{+} r$. Then, we will coordinate the supply chain.

\subsection{Centralized Decision}

We first consider a centralized decision on the order quantity in the channel. In this case, the channel profit is expressed as :

$$
\begin{aligned}
\pi(q) & =\int_{0}^{q} p x d F(x)+\int_{q}^{\infty} p q d F(x)+\int_{0}^{q}(q-x) s d F(x)-c q-(w q-B)^{+} r \\
& =q(p-c)-(p-s) \int_{0}^{q} F(x) d x-(w q-B)^{+} r
\end{aligned}
$$

When the revenue $(p x+s(q-x))$ is less than the capital gap involving the interest $\left((w q-B)^{+}(1+r)\right)$, the retailer will be bankrupt. Usually, the acceptable bankruptcy risk $\alpha$ should be set and the constraint is:

$$
p x+s(q-x) \geqslant(w q-B)^{+}(1+r)
$$

where demand $x$ affects the possibility of the capital breakage, measured by the acceptable bankruptcy risk $\alpha, x:=F^{-1}(\alpha)$. As a result,

$$
q \leqslant \frac{(p-s) F^{-1}(\alpha)+B(1+r)}{w(1+r)-s} .
$$


With the constraint of the bankruptcy risk, we obtain the following proposition.

Proposition 1. The retailer's optimal order quantity $q^{c}$ equal to: If $q_{s} \geqslant q_{t}, q^{c}=q_{t}$; if $q_{s}<q_{t}$, $q^{c}=q_{s}$, where $q_{s}=F^{-1}\left(\frac{p-c-w r}{p-s}\right)$ and $q_{t}=\frac{(p-s) F^{-1}(\alpha)+B(1+r)}{w(1+r)-s}$.

$q_{s}$ is the optimal order size without the bankruptcy risk and $q_{t}$ is the threshold that decide whether the bankruptcy risk is beyond $\alpha$. If $q_{s}<q_{t}$, then the bankruptcy risk with order size $q_{s}$ is not beyond the acceptable bankruptcy risk, then $q^{c}=q_{s}$. Otherwise, then the bankruptcy risk with order size $q_{s}$ is beyond the acceptable bankruptcy risk. Consequently, to control the bankruptcy risk below $\alpha$, the optimal order size should be $q^{c}=q_{t}$ (see Figure 1).

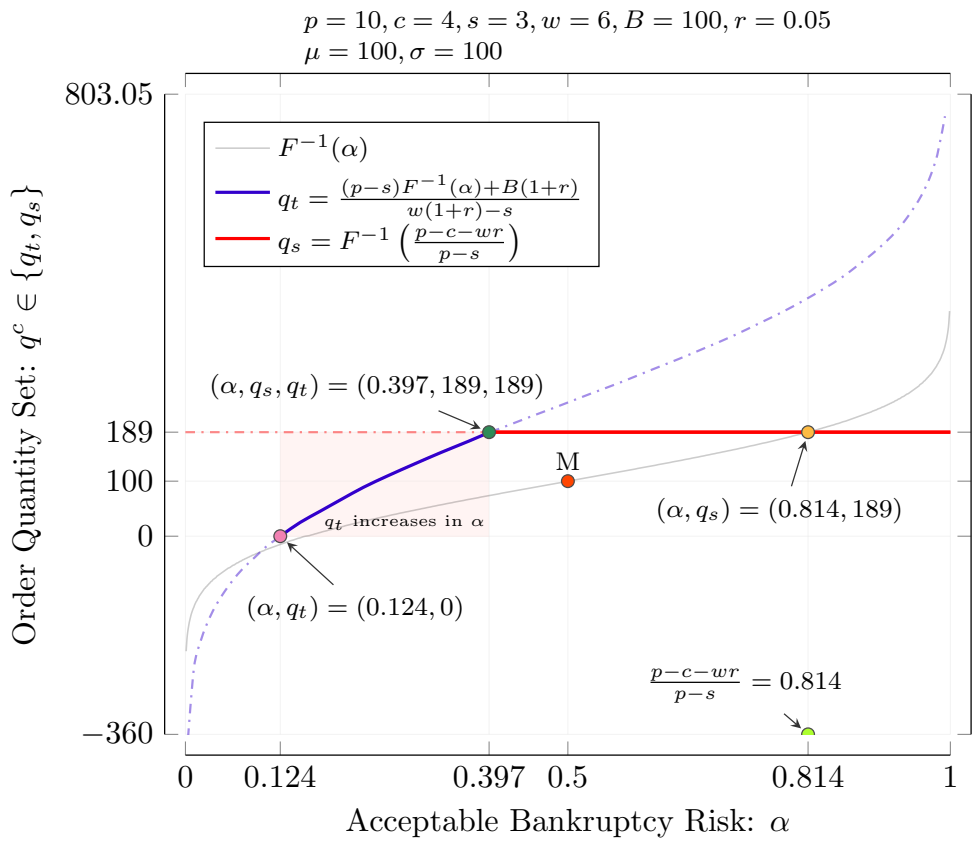

Figure 1. The impact of $\alpha$ on $q^{c}$ when the retailer is financially constrained.

Corollary 1. $q_{t}$ increases in $B$ and $\alpha$.

When the channel's own funds $B$ increase, the bankruptcy risk decreases such that the quantity threshold $q_{t}$ increases and it is more possible that $q_{s}<q_{t}$. When the maximum bankruptcy risk $\alpha$ increases, it is more possible that the optimal order quantity is not constraint with the threshold $q_{t}$ (see Figure 1).

Corollary 2. When $q_{s} \geqslant q_{t}, \pi^{\star}\left(q_{t}\right)$ increases in $\alpha$ and $B$.

When $q_{s}>q_{t}$, the optimal order size is a constraint with the channel's own funds and the acceptable bankruptcy risk. When $\alpha$ or $B$ increases, the constraint is more relaxed such that the quantity threshold $q_{t}$ is higher. Therefore, more own capital and higher acceptable bankruptcy risk $\alpha$ can increase the channel profit when the channel is under financial constraint (see Figure 2).

Next, we will consider the decentralized decision.

\subsection{Decentralized Decision}

In the decentralized decision, we design a coordinate contract, revenue-sharing and buy-back (RSBB) contract, in which the retailers decide the order quantity. The retailer's profit is: 


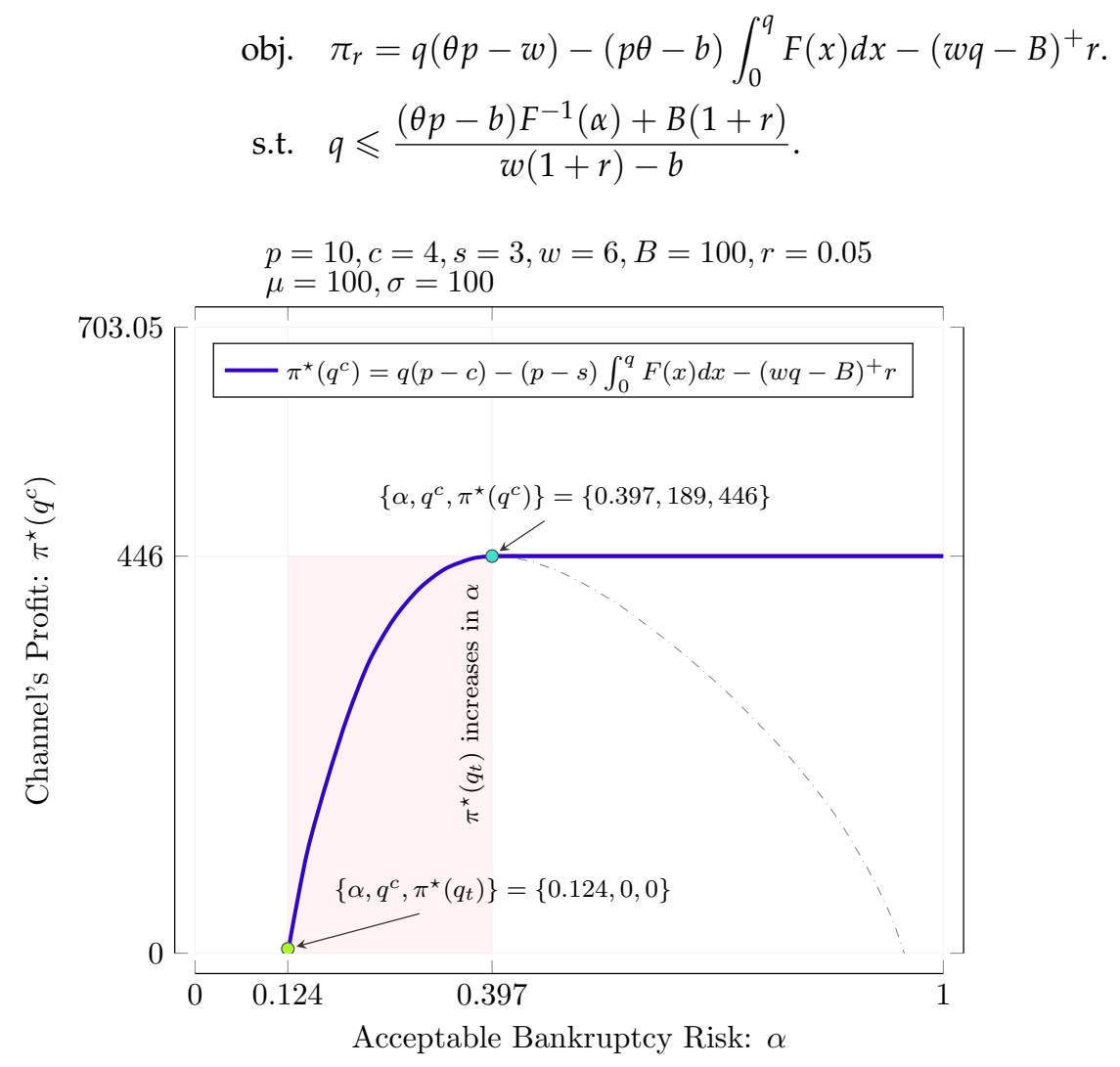

Figure 2. The impact of $\alpha$ on $\pi^{\star}\left(q^{c}\right)$ when the retailer is financially constrained.

In addition, the manufacturer's profit is:

$$
\begin{aligned}
\pi_{s} & =\int_{0}^{q}(1-\theta) p x d F(x)+\int_{q}^{\infty} p(1-\theta) q d F(x)+(s-b) \int_{0}^{q}(q-x) d F(x)-c q \\
& =q[(1-\theta) p+w-c]-[(1-\theta) p-s+b] \int_{0}^{q} F(x) d x .
\end{aligned}
$$

Similarly, we obtain that if $q_{s}^{d} \geqslant q_{t}^{d}, q \star=q_{t}^{d}$; if $q_{s}^{d}<q_{t}^{d}, q \star=q_{s}^{d}$, where $q_{s}^{d}=F^{-1}\left(\frac{\theta p-w(1+r)}{\theta p-b}\right)$ and $q_{t}^{d}=\frac{(\theta p-b) F^{-1}(\alpha)+B(1+r)}{w(1+r)-b}$ (see Figure 3). As the acceptable bankruptcy risk $\alpha$ increases, the threshold $q_{t}^{d}$ also increase. Additionally, the financial constraint is relaxed such that both $\pi_{s}$ and $\pi_{r}$ increase (see Figure 4).

\subsection{The Channel Coordination}

By using the RSBB contract, we coordinate the channel by making the decentralized decision equal to the centralized decision on the order quantity. Then, making $q_{t}=q_{t}^{d}$ and $q_{s}=q_{s}^{d}$, we have

$$
\begin{gathered}
\frac{p-c-w r}{p-s}=\frac{\theta p-w(1+r)}{\theta p-b} \\
\frac{(p-s) F^{-1}(\alpha)+B(1+r)}{w(1+r)-s}=\frac{(\theta p-b) F^{-1}(\alpha)+B(1+r)}{w(1+r)-b}
\end{gathered}
$$

Solving the function set above, we have the following result. 


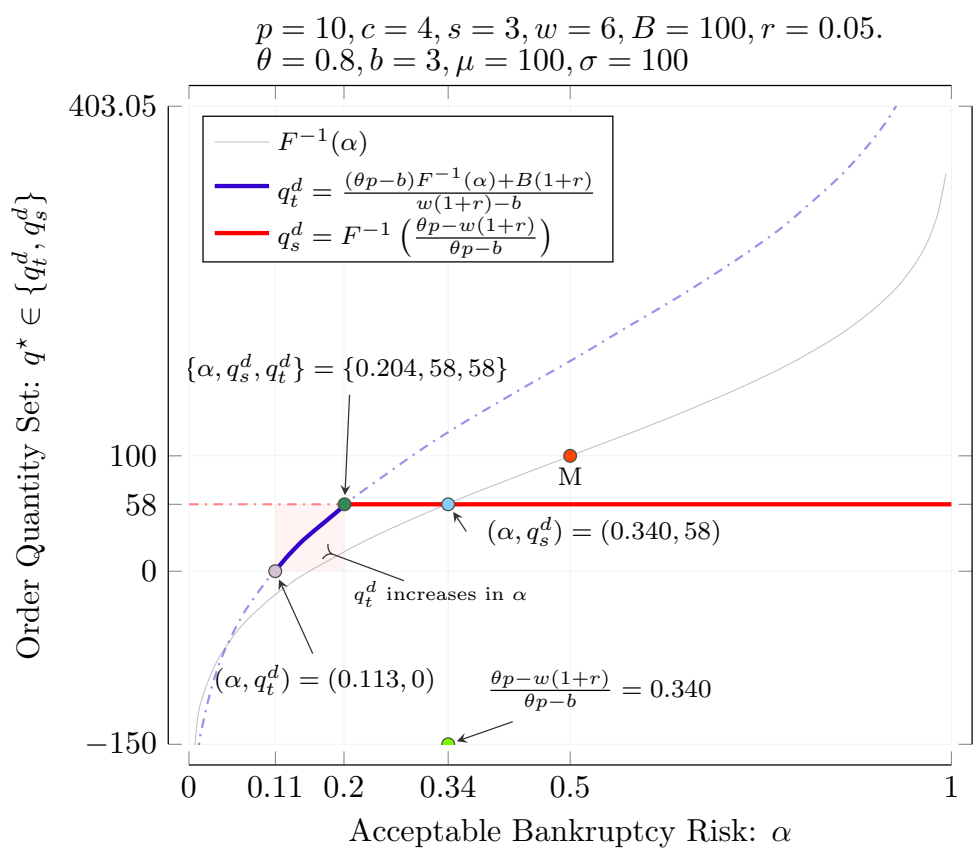

Figure 3. The impact of $\alpha$ on $q \star$ when the retailer has financial constraints.

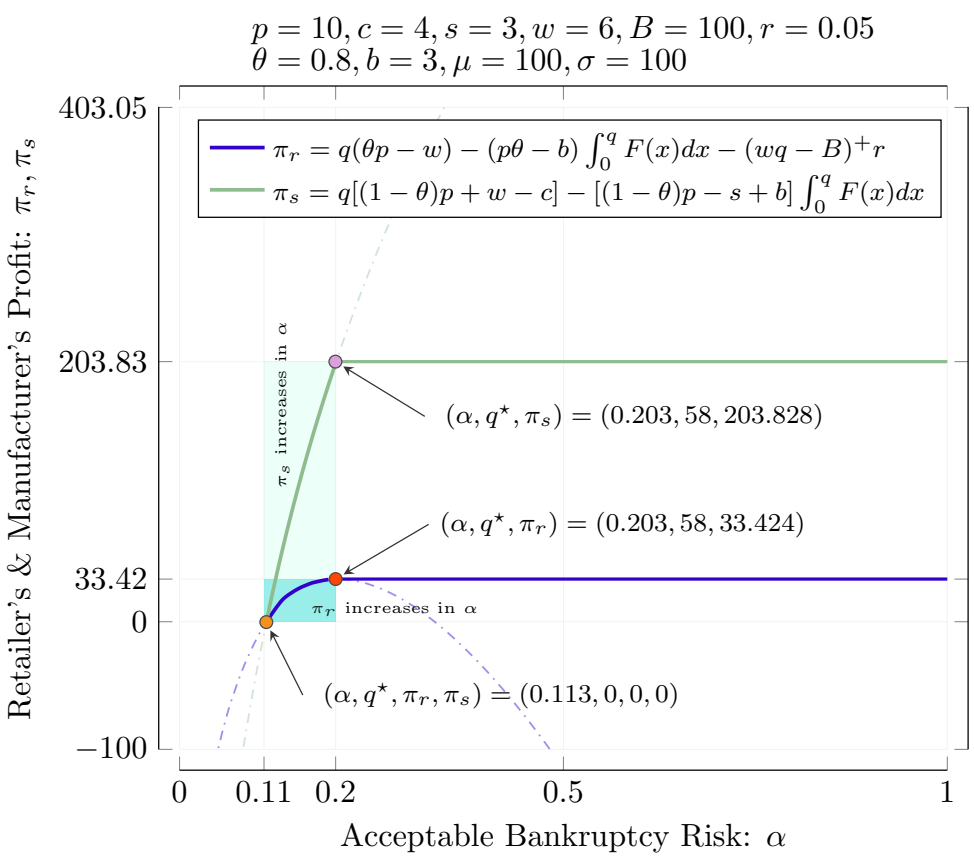

Figure 4. The impact of $\alpha$ on $\pi_{r}$ and $\pi_{s}$ when the retailer has financial constraints.

Proposition 2. When $\theta^{\star}=\frac{s B(1+r)(p-c-w r)+w(1+r)(p-s)\left[F^{-1}(\alpha)(w-c)-B(1+r)\right]}{p\left[F^{-1}(\alpha)(w-c)(p-s)+B(1+r)(s-c-w r)\right]}$, and $b^{\star}=\frac{(p-s)(w-c) w F^{-1}(\alpha)(1+r)+B s(1+r)(s-c-w r)}{F^{-1}(\alpha)(w-c)(p-s)+B(1+r)(s-c-w r)}$, the supply chain is coordinated.

In the RSBB contract, when the revenue share is $\theta^{\star}$ and the buy-back price is $b^{\star}$, then the supply chain is coordinated. The maximum channel profit can be realized in the decentralized decision.

Only when $p \theta^{\star}>b^{\star}$ is the retailer eager to sell. Otherwise, the retailer can make more profit by returning the goods to the manufacturer than by selling them to final customers such that the supply chain can not be coordinated. As shown in Figure 5, the comparison result between $p \theta^{\star}$ and $b^{\star}$ depends on the value of the acceptable bankruptcy risk $\alpha$. Only if 
$\alpha$ is below a certain level (such as 18\% in Figure 6), and the supply chain can be coordinated. In addition, when the supply chain can be coordinated ( $\alpha$ is below a certain level), the revenue share for the retailer $\theta^{\star}$ increases in the acceptable bankruptcy risk $\alpha$, but the buy-back price $b^{\star}$ decreases in $\alpha$.

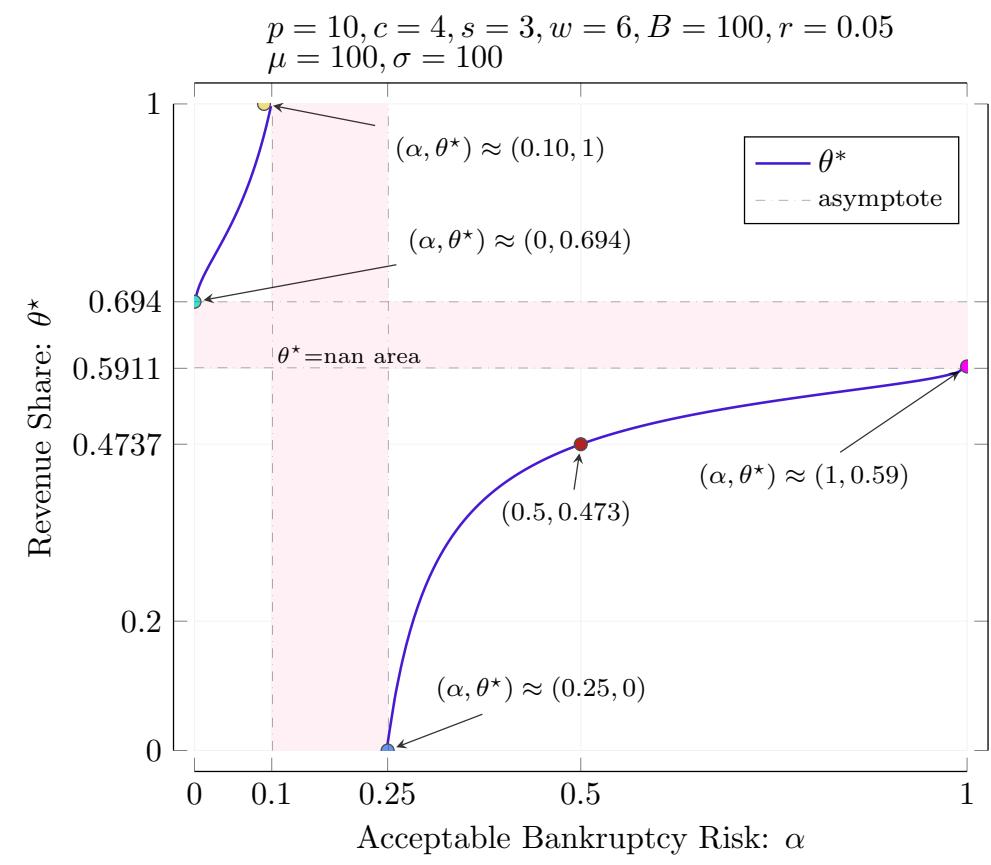

Figure 5. The impact of $\alpha$ on $\theta^{\star}$ when the retailer is financially constrained.

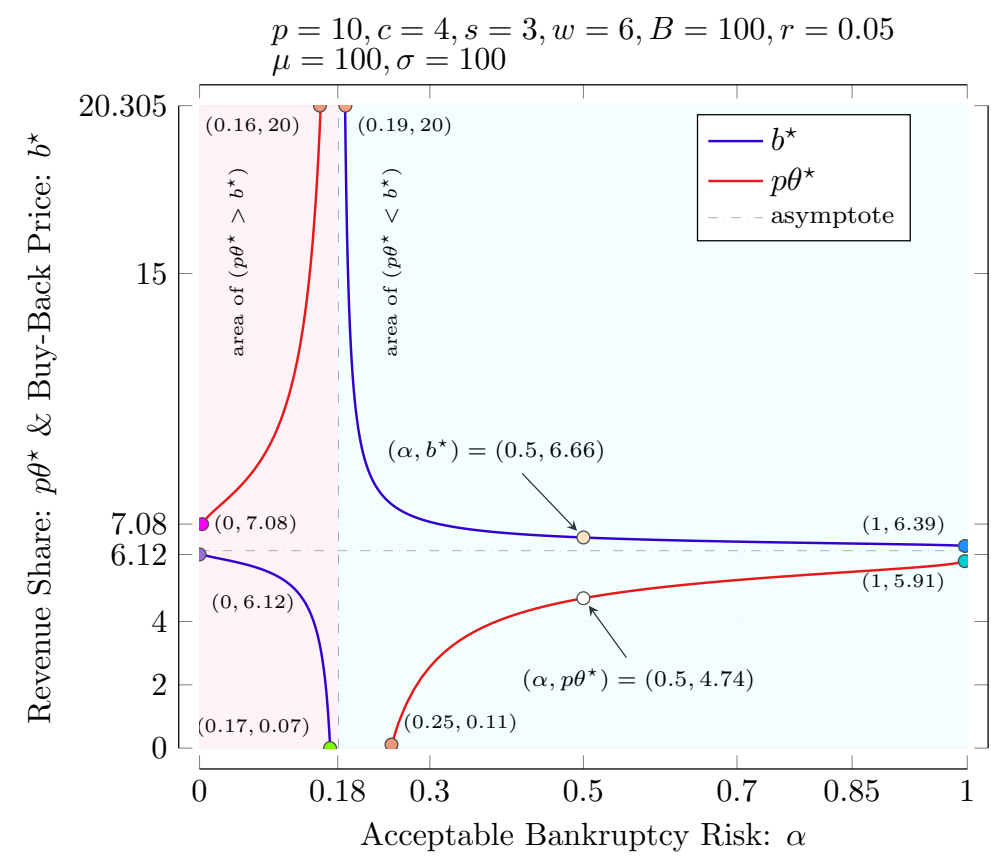

Figure 6. The impact of $\alpha$ on $b^{\star}$ and $p \theta^{\star}$ when the retailer is financially constrained.

\section{The Coordination When the Manufacturer Has Financial Constraints}

In this part, the retailer can pay a deposit (usually a part of the whole payment, denoted as $w$ per unit) to the manufacturer and the manufacturer needs to purchase materials to prepare the goods. Consequently, in this case, the manufacturer has financial constraints. The manufacturer's own capital is $B$. We also use the contract to coordinate the channel. 


\subsection{Centralized Decision}

In this part, the manufacturer and the retailer are considered as a whole part. The channel profits consist of the revenue, manufacturing cost, and the loan, interest fee. The profit is:

$$
\begin{aligned}
\tilde{\pi} & =\int_{0}^{q} p x d F(x)+\int_{q}^{\infty} p q d F(x)+\int_{0}^{q}(q-x) s d F(x)-c q-(c q-B)^{+} r \\
& =q(p-c)-(p-s) \int_{0}^{q} F(x) d x-(c q-B)^{+} r .
\end{aligned}
$$

When the revenue $(p x+s(q-x))$ is less than the capital gap involving the interest $\left((c q-B)^{+}(1+r)\right)$, the manufacturer will be bankrupt. Usually, the bankruptcy risk should be set and the constraint is:

$$
p x+s(q-x) \geqslant(c q-B)^{+}(1+r)
$$

Proposition 3. If $\tilde{q}_{s} \geqslant \tilde{q}_{t}, \tilde{q}^{c}=\tilde{q}_{t}$; if $\tilde{q}_{s}<\tilde{q}_{t}, \tilde{q}^{c}=\tilde{q}_{s}$, where $\tilde{q}_{s}=F^{-1}\left(\frac{p-c(1+r)}{p-s}\right)$ and $\tilde{q}_{t}=\frac{(p-s) F^{-1}(\alpha)+B(1+r)}{c(1+r)-s}$.

$\tilde{q}_{s}$ is the optimal order size without the bankruptcy risk and $q_{t}$ is the threshold that decides whether the bankruptcy risk is beyond $\alpha$. If $\tilde{q}_{s}<\tilde{q}_{t}$, then the bankruptcy risk with order size $\tilde{q}_{s}$ is not beyond the maximum bankruptcy risk, then $\tilde{q}_{c}=\tilde{q}_{s}$. Otherwise, the bankruptcy risk with order size $\tilde{q}_{s}$ is beyond the maximum bankruptcy risk. Consequently, in order to control the bankruptcy risk below $\alpha$, the optimal order size should be $\tilde{q}_{c}=\tilde{q}_{t}$ (see Figure 7).

Corollary 3. $\tilde{q}_{t}$ increases in $B$ and $\alpha$.

When the channel's own funds $B$ increase, the bankruptcy risk decreases such that the quantity threshold $\tilde{q}_{t}$ increases and it is more possible that $\tilde{q}_{s}<\tilde{q}_{t}$. When the maximum bankruptcy risk $\alpha$ increases, it is more possible that the optimal order quantity is not constraint with the threshold $\tilde{q}_{t}$ (see Figure 7).

Corollary 4. When $\tilde{q}_{s}>\tilde{q}_{t}, \tilde{\pi}^{\star}\left(\tilde{q}_{t}\right)$ increases in $\alpha$ and $B$.

When $\tilde{q}_{s}>\tilde{q}_{t}$, the optimal order size is a constraint with the channel's own funds and the maximum bankruptcy risk. When $\alpha$ or $B$ increases, the constraint is more relaxed such that the quantity threshold $\tilde{q}_{t}$ is higher. Therefore, more own capital and higher acceptable bankruptcy risk $\alpha$ can increase the channel profit when the channel is under financial constraint (see Figure 8).

The financial constraint affects the channel profit maximization if and only if $\tilde{q}^{s}>\tilde{q}^{t}$, which leads to

$$
F^{-1}\left(\frac{p-c(1+r)}{p-s}\right) \geqslant \frac{(p-s) F^{-1}(\alpha)+B(1+r)}{c(1+r)-s} .
$$

Then

$$
\begin{aligned}
& B \leqslant(c(1+r)-s) F^{-1}\left(\frac{p-c(1+r)}{p-s}\right)-(p-s) F^{-1}(\alpha) \\
& \alpha \leqslant F\left(\frac{[c(1+r)-s] F^{-1}\left(\frac{p-c(1+r)}{p-s}\right)-B(1+r)}{p-s}\right) .
\end{aligned}
$$


Make

$$
\begin{aligned}
& \bar{B}=(c(1+r)-s) F^{-1}\left(\frac{p-c(1+r)}{p-s}\right)-(p-s) F^{-1}(\alpha) \\
& \bar{\alpha}=F\left(\frac{[c(1+r)-s] F^{-1}\left(\frac{p-c(1+r)}{p-s}\right)-B(1+r)}{p-s}\right) .
\end{aligned}
$$

$\bar{B}$ decreases in $\alpha$, and $\bar{\alpha}$ decreases in $B$. Summarizing the results above, we have the following proposition.

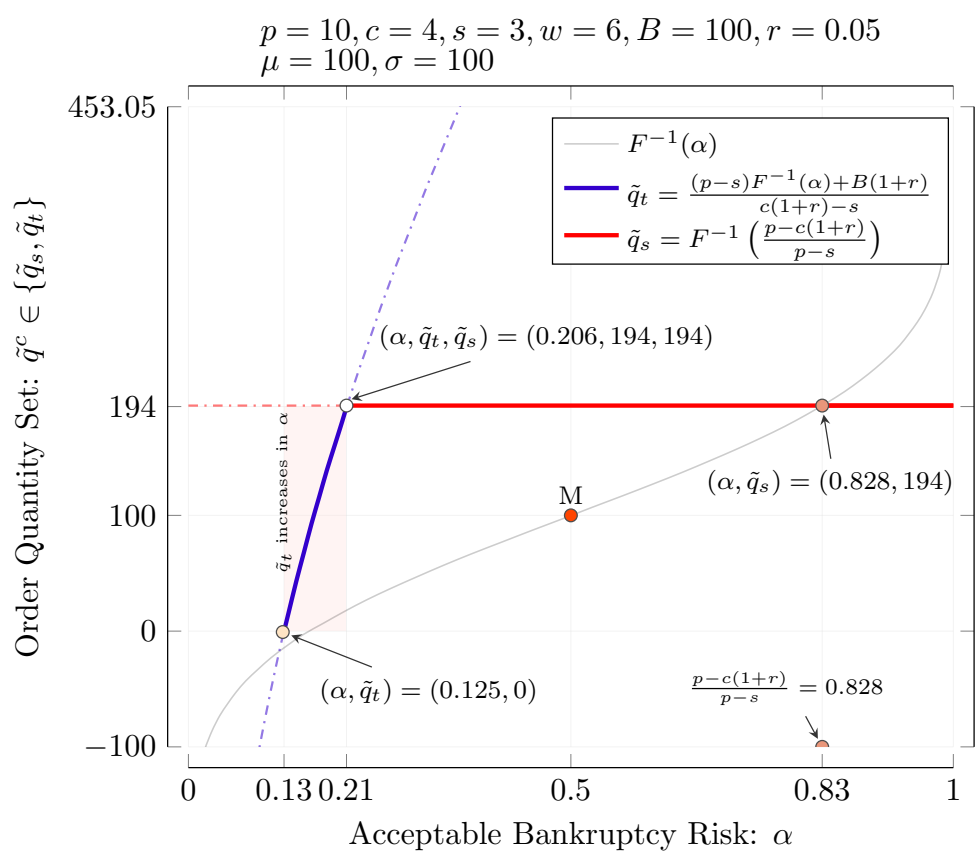

Figure 7. The impact of $\alpha$ on $\tilde{q}^{c}$ when the manufacturer has financial constraints.

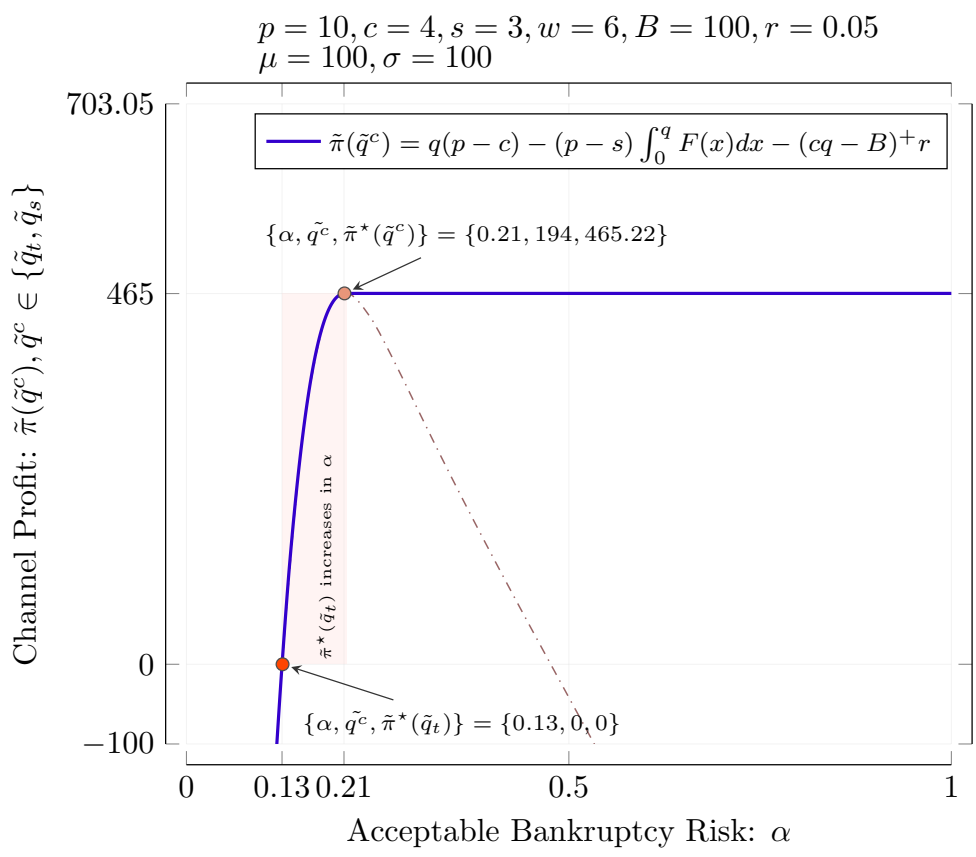

Figure 8. The impact of $\alpha$ on $\tilde{\pi}$ when the manufacturer has financial constraints. 
Proposition 4. When $B \leqslant \bar{B}$ or $\alpha \leqslant \bar{\alpha}$, the channel maximization is constraint with the capital. Besides, $\bar{B}$ decreases in $\alpha$ and $\bar{\alpha}$ decreases in $B$.

We find a threshold of the manufacturer's own funds $\bar{B}$, and a threshold of the acceptable bankruptcy risk $\alpha$ that both decide whether the channel is a constraint to the capital. The channel will be a constraint to the capital only if their own funds are few, such that $B \leqslant \bar{B}$ or the acceptable bankruptcy risk is low such that $\alpha \leqslant \bar{\alpha}$. In addition, the acceptable bankruptcy risk increases and the threshold of the manufacturer's own funds $\bar{B}$ can be decreased (see Figure 9). Whereas, when the manufacturer's own funds increase, the threshold of the acceptable bankruptcy risk can be decreased. Therefore, increasing the own funds or acceptable bankruptcy risk is a way to reduce or even remove the financial restriction of the channel (see Figure 10).

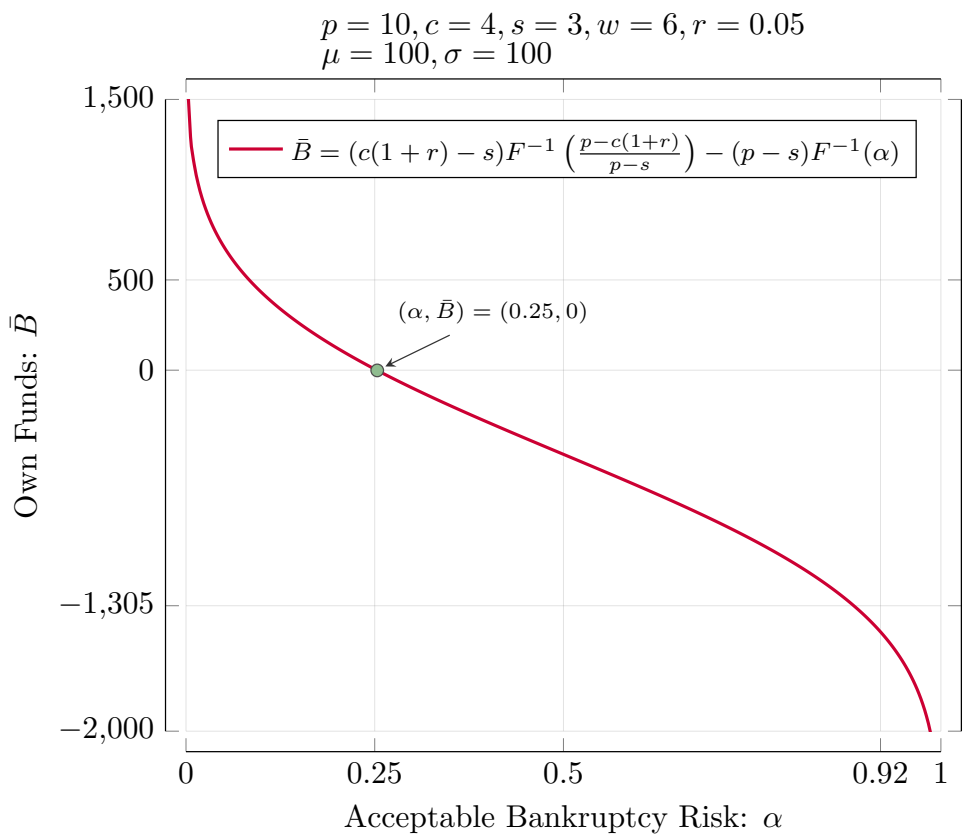

Figure 9. The impact of $\alpha$ on $\bar{B}$ when the manufacturer has financial constraints.

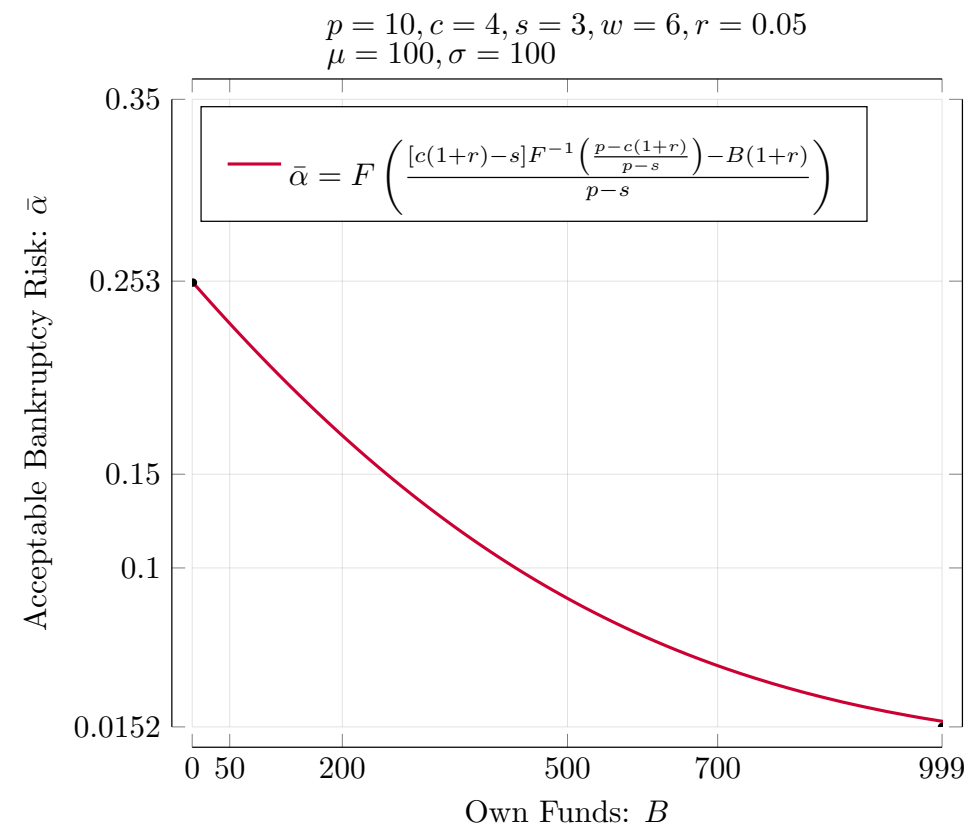

Figure 10. The impact of $B$ on $\bar{\alpha}$ when the manufacturer has financial constraints. 
Next, we will consider the decentralized decision.

\subsection{Decentralized Decision}

In the decentralized decision, we design a coordinate contract and a revenue-sharing and buy-back (RSBB) contract, in which the retailers decide the order quantity. The retailer's profit is:

$$
\tilde{\pi}_{r}=q(\theta p-w)-(p \theta-b) \int_{0}^{q} F(x) d x .
$$

The manufacturer's profit is:

$$
\tilde{\pi}_{s}=\pi-\pi_{r}=q[(1-\theta) p+w-c]-[(1-\theta) p-s+b] \int_{0}^{q} F(x) d x-(c q-B)^{+} r .
$$

Because the manufacturer has financial constraints and needs to borrow money from the bank, then the manufacturer might possibly breakup. The possibility of a breakup is measured by the $\alpha$, the corresponding demand is $x=F^{-1}(\alpha)$. Then

$$
(1-\theta) p x+(s-b)(q-x) \geqslant[(c-w) q-B](1+r) .
$$

Or

$$
q \leqslant \frac{[(1-\theta) p+b-s] x+B(1+r)}{(c-w)(1+r)+b-s} .
$$

Let $\tilde{q}_{t}^{d}=\frac{[(1-\theta) p+b-s] x+B(1+r)}{(c-w)(1+r)+b-s}$. Taking the first-order derivative of $\pi_{r}$ with respect to $q$, we obtain

$$
\frac{\partial \tilde{\pi}_{r}}{\partial q}=(\theta p-w)-(\theta p-b) F(q) .
$$

$\frac{\partial \tilde{\pi}_{r}}{\partial q}$ decreases in $q$. Making $\frac{\partial \tilde{\pi}_{r}}{\partial q}=0$, we obtain $\tilde{q}_{s}^{d}=F^{-1}\left(\frac{\theta p-w}{\theta p-b}\right)$.

\subsection{The Coordination}

By using the RSBB contract, we coordinate the channel by making the decentralized decision equal to the centralized decision on the order quantity. To coordinate the channel, $q_{t}=\tilde{q}_{t}^{d}$ and $q_{s}=\tilde{q}_{s}^{d}$. Then

$$
\begin{aligned}
\frac{p-c(1+r)}{p-s} & =\frac{\theta p-w}{\theta p-b} \\
\frac{(p-s) F^{-1}(\alpha)+B(1+r)}{c(1+r)-s} & =\frac{[(1-\theta) p+b-s] F^{-1}(\alpha)+B(1+r)}{(c-w)(1+r)+b-s} .
\end{aligned}
$$

Solving the function set above, we have the following result.

Proposition 5. When $\tilde{\theta}^{*}=\frac{B w(p-s)(1+r)-B w(1+r)^{2}[p-c(1+r)]-w r F^{-1}(\alpha)(p-s)[p-c(1+r)]}{p B(1+r)[c(1+r)-s]}$ and $\tilde{b}^{*}=\frac{w\left[B(1+r)^{2}+r F^{-1}(\alpha)(p-s)\right]}{B(1+r)}$, the supply chain is coordinated.

In the RSBB contract, when the revenue share is $\tilde{\theta}^{*}$ and the buy-back price is $\tilde{b}^{*}$, then the supply chain is coordinated. The maximum channel profit can be realized in the decentralized decision.

Only when $p \theta^{\star}>b^{\star}$ is the retailer eager to sell. Otherwise, the retailer can make more profit by returning the goods to the manufacturer than by selling them to final customers such that the supply chain can not be coordinated. As shown in Figure 11, the comparison result between $p \theta^{\star}$ and $b^{\star}$ depends on the value of the acceptable bankruptcy 
risk $\alpha$. Only if $\alpha$ is below a certain level (such as $12.5 \%$ in Figure 11 ) then the supply chain can be coordinated.

When the supply chain can be coordinated and the manufacturer has financial constraint ( $\alpha$ is below a certain level), the revenue share for the retailer $\theta^{\star}$ decreases in the acceptable bankruptcy risk $\alpha$, but the buy-back price $b^{\star}$ increases in $\alpha$. The result is different from the case when the retailer has financial constraints.

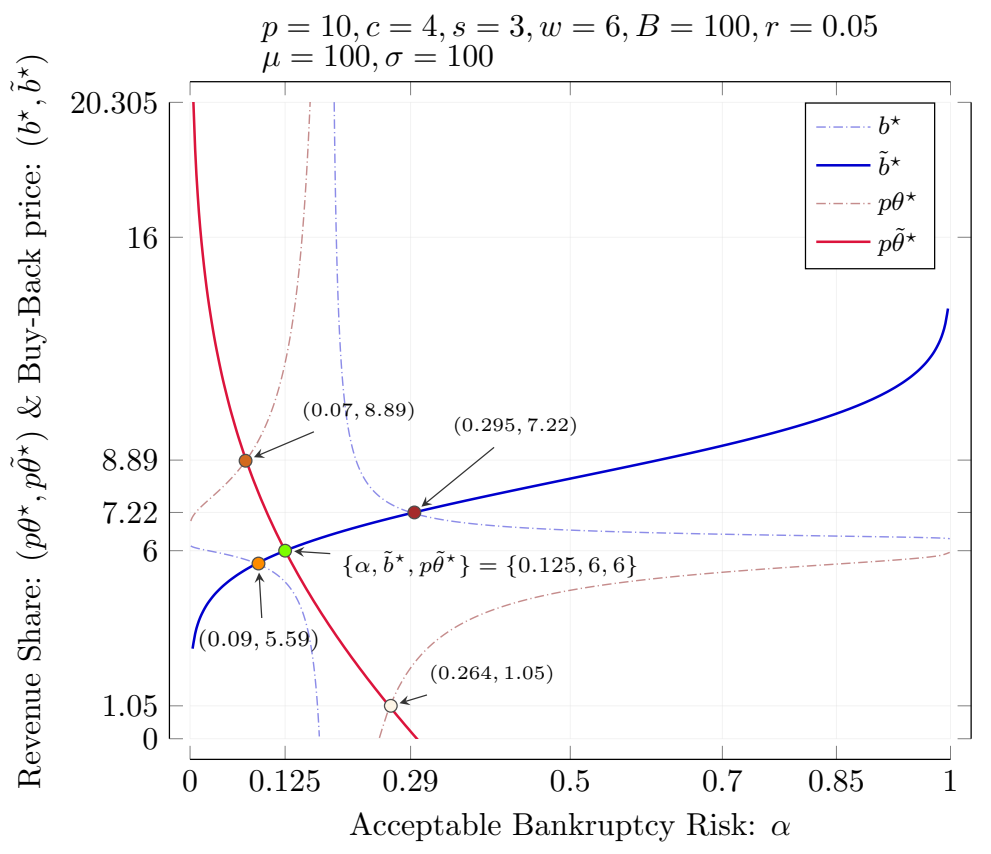

Figure 11. The impact of $\alpha$ on $b^{\star}$ and $p \tilde{\theta}^{\star}$ when the manufacturer has financial constraints.

\section{Conclusions}

In recent years, increasingly companies are incorporating sustainability into their SCM practices. The goal is to realize the sustainability of products, services, capital, etc., to create maximum value for all business stakeholders [30]. To do this, according to the characteristics of the supply chain, it is necessary to design an appropriate contract to eliminate double marginalization. The supply chain can be coordinated by the contract. We focus on the contract design to coordinate the supply chain of NEVs, especially in the context of uncertain demand and capital constraints of NEV companies. Considering the sustainability of new energy industries is important for energy and global environmental protection. We examine the impact of the RSBB contract coordination factor on the retailer's optimal order quantity decision from a corporate sustainability (CS) standpoint, using the firms' acceptable bankruptcy risk (ABR) as a lens. More specifically, we design an RSBB contract to coordinate the NEV supply chain with the cash-strapped retailer or manufacturer and analyze the impact of the acceptable bankruptcy risk on the optimal order quantity, supply chain profit, and coordinate factors, including revenue-share and buy-back price. We find that no matter if the manufacturer or retailer is cash-strapped, both the optimal order quantity and the maximum supply chain profit increase with the acceptable bankruptcy risk. In addition, the revenue share decreases in the acceptable bankruptcy risk, but the buy-back price increases in the acceptable bankruptcy risk when the retailer is cash-strapped. However, when the manufacturer is cash-strapped, the revenue share increases in the acceptable bankruptcy risk, but the buy-back price decreases in the acceptable bankruptcy risk.

The practice management significance to the SSCM field is: In a NEV industry with market uncertainty, (1) If a financially constrained retailer prefers a low acceptable bankruptcy risk, then the optimal decision for the manufacturer under RSBB's contractual coordination is to increase the revenue sharing ratio and reduce the buy-back price to 
incentivize the retailer to increase the optimal order quantity. If the retailer's preference is high acceptable bankruptcy risk, the relationship may be undesirable in a supply chain where the retailer has no incentive to work hard because the buy-back price is higher than the revenue sharing ratio. (2) If a financially constrained manufacturer prefers a low acceptable bankruptcy risk, the best decision for the manufacturer under the RSBB contract is to reduce the revenue share while increasing the buy-back price to incentivize the retailer to increase the optimal order quantity. When the manufacturer prefers a high acceptable bankruptcy risk, supply chain coordination becomes meaningless.

We only combine revenue share and buy-back contracts to coordinate the cashstrapped supply chain. The research can be extended to other forms of the supply chain contracts, such quantity flexibility and sales rebate. We leave it for further research.

Author Contributions: Conceptualization, X.L. and Y.L.; methodology, X.L.; software, Y.L.; validation, X.L. and Y.L.; formal analysis, X.L. and Y.L.; investigation, X.L. and Y.L.; resources, X.L.; data curation, Y.L.; writing-original draft preparation, X.L. and Y.L.; writing-review and editing, X.L. and Y.L.; visualization, Y.L.; supervision, X.L.; project administration, X.L. and Y.L.; funding acquisition, X.L. All authors have read and agreed to the published version of the manuscript.

Funding: This research was funded by the National Natural Science Foundation of China under Grant No. 71801233 and Department of Science and Technology of Guangdong Province (Grant No. 2020A0505090004).

Data Availability Statement: The data used to support the findings of this study are included within the article. More (e.g., Python and TikZ source code and data, etc.) can be downloaded from the author's Github: https://github.com/iihciyekub/sustainability-1485080-data (accessed on 12 January 2022).

Acknowledgments: The authors thank the editor and three anonymous reviewers of the paper. Their constructive suggestions and comments have considerably improved the quality of the paper.

Conflicts of Interest: The authors declare no conflict of interest.

\section{Abbreviations}

The following abbreviations are used in this manuscript:

$\begin{array}{ll}\text { CSR } & \text { Corporate Social Responsible } \\ \text { NEV } & \text { New Energy Vehicles } \\ \text { SC } & \text { Supply Chain } \\ \text { SCF } & \text { Supply Chain Financing } \\ \text { SCM } & \text { Supply Chain Management } \\ \text { SSCM } & \text { Sustainable Supply Chain Management } \\ \text { RS } & \text { Revenue-Sharing Contract } \\ \text { WP } & \text { Wholesale-Price Contract } \\ \text { CS } & \text { Cost-Sharing Contract } \\ \text { IS } & \text { Investment-Sharing Contract } \\ \text { QD } & \text { Quantity-Discount Contract } \\ \text { APD } & \text { Advance-Purchase Discount Contract } \\ \text { TPTF } & \text { Two-Part Tariff Contract } \\ \text { RSBB } & \text { Revenue-Sharing and Buy-Back Contract } \\ \text { RGMS } & \text { Revenue and Green Marketing Cost-sharing Contract }\end{array}$

\section{Appendix A. Proofs}

In this part, we provide the detailed proofs of our results in the main paper.

Appendix A.1. Proof of Proposition 1

Proof. Simplify (2) and $x:=F^{-1}(\alpha)$

$$
q \leqslant \frac{(p-s) F^{-1}(\alpha)+B(1+r)}{w(1+r)-s} .
$$


By the Lagrange function, we obtain

$$
L(q)=q(p-c)-(p-s) \int_{0}^{q} F(x) d x-(w q-B)^{+} r+\eta_{1}\left[\frac{(p-s) F^{-1}(\alpha)+B(1+r)}{w(1+r)-s}-q\right] .
$$

Taking the first-order derivative of $L$ with respect to $q$, we obtain

$$
\frac{\partial L}{\partial q}=(p-c)-(p-s) F(q)-w r-\eta_{1} .
$$

The KKT condition is

$$
\eta_{1}\left[\frac{(p-s) F^{-1}(\alpha)+B(1+r)}{w(1+r)-s}-q\right] \geqslant 0 .
$$

Obviously, $\frac{\partial L}{\partial q}$ decreases in $q$. Making the $\frac{\partial L}{\partial q}=0$, we obtain that if $q_{s} \geqslant q_{t}, q^{c}=q_{t}$; if $q_{s}<q_{t}, q^{c}=q_{s}$, where $q_{s}=F^{-1}\left(\frac{p-c-w r}{p-s}\right)$ and $q_{t}=\frac{(p-s) F^{-1}(\alpha)+B(1+r)}{w(1+r)-s}$.

Appendix A.2. Proof of Proposition 2

Proof. $x$ depends on the possibility of the capital breakage, measured acceptable bankruptcy risk $\alpha$. As a result,

$$
q \leqslant \frac{(p-s) F^{-1}(\alpha)+B(1+r)}{c(1+r)-s} .
$$

By the Lagrange function, we obtain

$$
L(q)=q(p-c)-(p-s) \int_{0}^{q} F(x) d x-(c q-B)^{+} r+\eta_{1}\left[\frac{(p-s) F^{-1}(\alpha)+B(1+r)}{c(1+r)-s}-q\right] .
$$

Taking the first-order derivative of $L$ with respect to $q$, we obtain

$$
\frac{\partial L}{\partial q}=(p-c)-(p-s) F(q)-c r-\eta_{1}
$$

The KKT condition is

$$
\eta_{1}\left[\frac{(p-s) F^{-1}(\alpha)+B(1+r)}{c(1+r)-s}-q\right] \geqslant 0 .
$$

Obviously, $\frac{\partial L}{\partial q}$ decreases in $q$. Making the $\frac{\partial L}{\partial q}=0$, we obtain that if $\tilde{q}_{s} \geqslant \tilde{q}_{t}, \tilde{q}^{c}=\tilde{q}_{t} ;$ if $\tilde{q}_{s}<\tilde{q}_{t}, \tilde{q}^{c}=\tilde{q}_{s}$, where $\tilde{q}_{s}=F^{-1}\left(\frac{p-c(1+r)}{p-s}\right)$ and $\tilde{q}_{t}=\frac{(p-s) F^{-1}(\alpha)+B(1+r)}{c(1+r)-s}$.

Obviously, $\tilde{q}_{t}$ increases in $B$ and $\alpha$.

\section{References}

1. Wu, Y.; Zhang, L. Can the development of electric vehicles reduce the emission of air pollutants and greenhouse gases in developing countries? Transp. Res. Part D-Transp. Environ. 2017, 51, 129-145. [CrossRef]

2. Gong, B.; Xia, X.; Cheng, J. Supply-Chain Pricing and Coordination for New Energy Vehicles Considering Heterogeneity in Consumers' Low Carbon Preference. Sustainability 2020, 12, 1306. [CrossRef]

3. Zhu, W.; He, Y. Green product design in supply chains under competition. Eur. J. Oper. Res. 2017, 258, 165-180. [CrossRef]

4. Yu, Y.; Zhou, D.; Zha, D.; Wang, Q. Joint optimization of charging facility investment and pricing in automobile retail supply chain and coordination. Comput. Ind. Eng. 2021, 156. [CrossRef]

5. Srinivasa Raghavan, N.R.; Mishra, V.K. Short-term financing in a cash-constrained supply chain. Int. J. Prod. Econ. 2011, 134, 407-412. [CrossRef]

6. Hertzel, M.; Li, Z.; Officer, M.; Rodgers, K. Inter-firm linkages and the wealth effects of financial distress along the supply chain. J. Financ. Econ. 2008, 87, 374-387. [CrossRef]

7. Gong, H.; Wang, M.Q.; Wang, H. New energy vehicles in China: Policies, demonstration, and progress. Mitig. Adapt. Strateg. Glob. Chang. 2013, 18, 207-228. [CrossRef] 
8. Zhang, X.; Wang, K.; Hao, Y.; Fan, J.L.; Wei, Y.M. The impact of government policy on preference for NEVs: The evidence from China. Energy Policy 2013, 61, 382-393. [CrossRef]

9. Wang, Z.; Zhao, C.; Yin, J.; Zhang, B. Purchasing intentions of Chinese citizens on new energy vehicles: How should one respond to current preferential policy? J. Clean. Prod. 2017, 161, 1000-1010. [CrossRef]

10. Song, Q.N. Study on the Mechanism for Profit Distribution in Energy Supply Chain. Adv. Mater. Res. 2013, 734-737, 1772-1780. [CrossRef]

11. Linton, J.D.; Klassen, R.; Jayaraman, V. Sustainable supply chains: An introduction. J. Oper. Manag. 2007, 25, 1075-1082. [CrossRef]

12. Carter, C.R.; Rogers, D.S. A framework of sustainable supply chain management: Moving toward new theory. Int. J. Phys. Distrib. Logist. Manag. 2008, 38, 360-387. [CrossRef]

13. Carter, C.R.; Easton, P.L. Sustainable supply chain management: Evolution and future directions. Int. J. Phys. Distrib. Logist. Manag. 2011, 41, 46-62. [CrossRef]

14. Beske, P.; Seuring, S. Putting sustainability into supply chain management. Supply Chain. Manag.-Int. J. 2014, 19, 322-331. [CrossRef]

15. Dubey, R.; Gunasekaran, A.; Papadopoulos, T.; Childe, S.J.; Shibin, K.T.; Wamba, S.F. Sustainable supply chain management: Framework and further research directions. J. Clean. Prod. 2017, 142, 1119-1130. [CrossRef]

16. Panda, S. Coordination of a socially responsible supply chain using revenue sharing contract. Transp. Res. Part E-Logist. Transp. Rev. 2014, 67, 92-104. [CrossRef]

17. Hsueh, C.F. Improving corporate social responsibility in a supply chain through a new revenue sharing contract. Int. J. Prod. Econ. 2014, 151, 214-222. [CrossRef]

18. Wu, Y.; Li, H.; Gou, Q.; Gu, J. Supply chain models with corporate social responsibility. Int. J. Prod. Res. 2017, 55, 6732-6759. [CrossRef]

19. Closs, D.J.; Speier, C.; Meacham, N. Sustainability to support end-to-end value chains: The role of supply chain management. $J$. Acad. Mark. Sci. 2011, 39, 101-116. [CrossRef]

20. Hong, Z.; Guo, X. Green product supply chain contracts considering environmental responsibilities. Omega 2019, 83, 155-166. [CrossRef]

21. Kouvelis, P.; Zhao, W. The Newsvendor Problem and Price-Only Contract When Bankruptcy Costs Exist. Prod. Oper. Manag. 2011, 20, 921-936. [CrossRef]

22. Kouvelis, P.; Zhao, W. Financing the newsvendor: Supplier vs. bank, and the structure of optimal trade credit contracts. Oper. Res. 2012, 60, 566-580. [CrossRef]

23. Kouvelis, P.; Zhao, W. Supply Chain Contract Design Under Financial Constraints and Bankruptcy Costs. Manag. Sci. 2016, 62, 2341-2357. [CrossRef]

24. Feng, X.; Moon, I.; Ryu, K. Supply chain coordination under budget constraints. Comput. Ind. Eng. 2015, 88, 487-500. [CrossRef]

25. Xiao, S.; Sethi, S.P.; Liu, M.; Ma, S. Coordinating contracts for a financially constrained supply chain. Omega-Int. J. Manag. Sci. 2017, 72, 71-86. [CrossRef]

26. He, Y.; Zhao, X. Contracts and Coordination: Supply Chains with Uncertain Demand and Supply. Nav. Res. Logist. 2016, 63, 305-319. [CrossRef]

27. Xing, G.; Xia, B.; Guo, J. Sustainable Cooperation in the Green Supply Chain under Financial Constraints. Sustainability 2019, 11, 5977. [CrossRef]

28. Li, T.; Zhang, R.; Zhao, S.; Liu, B. Low carbon strategy analysis under revenue-sharing and cost-sharing contracts. J. Clean. Prod. 2019, 212, 1462-1477. [CrossRef]

29. Xin, C.; Chen, X.; Chen, H.; Chen, S.; Zhang, M. Green Product Supply Chain Coordination Under Demand Uncertainty. IEEE Access 2020, 8, 25877-25891. [CrossRef]

30. Wolf, J. Sustainable Supply Chain Management Integration: A Qualitative Analysis of the German Manufacturing Industry. J. Bus. Ethics 2011, 102, 221-235. [CrossRef] 